\title{
CIDADE, MONUMENTALIDADE E PODER
}

\author{
CRISTIANE MOREIRA RODRIGUES*
}

\begin{abstract}
(...) Em toda parte a monumentalidade se difunde, se irradia, se condensa, se concentra. Um momento vai além de si próprio, de sua fachada (se tem uma), de seu espaço interno. A monumentalidade pertencem, em geral, a altura e a profundidade, a amplitude de um espaço que ultrapassa seus limites materiais. (LEFEBVRE, 1999, p. 46, grifo do autor)
\end{abstract}

\section{Introduzindo o tema}

Do sucesso cinematográfico "Titanic" (1998), de James Cameron, destacamos, aqui, um curto diálogo travado entre o idealizador do majestoso navio, Bruce Smay, o seu construtor, Sr. Andrews, e a "nova-rica" Margareth Brown (apelidada de Molly). Tendo como tema da conversa o próprio Titanic, dizem eles:

Bruce Smay: - É o maior objeto que se move já criado pela mão do Homem em toda a história. E nosso principal construtor, o Sr. Andrews, o projetou desde a quilha.

Andrews: - Bem, eu posso ter construído rapidamente, mas a idéia foi do Sr. Smay. Ele imaginou um vapor tão grande em escala, e tão luxuoso, que sua supremacia jamais seria desafiada. E cá está ele: um sonho que se torna realidade.

Molly: - Rapaz, quem pensou nesse nome - Titanic? Foi você, Bruce?...

Bruce Smay: - Na verdade, foi. Eu quis me referir ao tamanho. E tamanho significando estabilidade, luxo, e, acima de tudo, força.

Sabemos que, apesar do filme partir de fatos reais, ele se utiliza destes para contar a sua história de ficção. No entanto, é difícil não imaginar (como o fez o roteirista), um tal diálogo sendo realizado enquanto gigantescos mecanismos moviam igualmente gigantescas hélices, que, por sua vez, conduziam o portentoso navio. Afinal, muito além de ser pensado como cumpridor de uma função - transportar pessoas e cargas através dos oceanos - o objeto Titanic certamente foi idealizado como um símbolo que deveria transmitir uma mensagem (para os que o olhassem ou dele tomassem conhecimento). E, para simbolizar o que queria - a estabilidade, o luxo e, principalmente, a força - , seu idealizador, quando sonhou, não encontrou (ou não desejou) um outro meio de fazê-lo que não recorrendo à monumentalidade. Só através de uma forma monumental a idéia a ser representada poderia tornar-se fato, e, o sonho, realidade, pois só assim ganharia notoriedade. E essa notoriedade foi conseguida, tanto na breve duração do navio, quanto, e mais ainda, após o seu naufrágio, porque além deste levar consigo centenas de vidas, levou também a frustração de ambiciosas aspirações. Pensamos que essa história não seria tão lembrada e recontada se não fosse o Titanic tão monumental.

A monumentalidade atua na dimensão do simbólico, dando visualidade, representando e valorizando as idéias, ações e concepções daqueles que a utilizam. Ela tem sempre uma razão de ser, a qual pode estar bem explicitada ou não. A monumentalidade se difunde e se concentra, como diz Lefebvre, nas mais variadas formas, e aqueles que habitam as cidades, especialmente (mas não unicamente) os grandes centros e capitais, com ela convivem e a admiram ou odeiam, por ela são intimidados, e, às vezes, a ela tentam desafiar.

Enquanto o vaidoso Bruce Smay sonhava em atribuir monumentalidade a um objeto, a uma

\footnotetext{
* Mestra pelo Programa de Pós Graduação em Geografia da UFRJ
} 
máquina móvel, muitos - anteriores, contemporâneos e posteriores a ele - tentaram ou construiram a monumentalidade na/da cidade. Preencheram ou tentaram preencher esta com seus símbolos, a fim de gravar no espaço a marca dos seus poderes e a força da ideologia que os estava guiando.

\section{Buscando uma conceitualização}

Uma primeira dificuldade que se nos apresenta quando buscamos informações acerca dos conceitos de monumento e monumentalidade é a escassez de uma bibliografia que nos ofereça estudos amplos e sistemáticos sobre o assunto.

Apesar de a monumentalidade nas cidades ser percebida ou descrita por vários autores que tratam de uma historiografia urbana, como Lewis Mumford (1982) e Leonardo Benevolo (1983), entre outros, ela raramente é tratada de forma teórico-conceitual. Mesmo sendo um fenômeno universal, presente tanto nas cidades reais quanto nas cidades idealizadas das utopias e dos planos não realizados, a monumentalidade em si, como opção por um modelo urbano e como elemento denotador de significados políticos, econômicos e sociais, raras vezes foi o escopo de tratamentos teóricos diretos e sistemáticos.

Apenas um pouco mais acessível é a bibliografia sobre monumentos. Enquanto o substantivo concreto "monumento" ainda é definido e analisado por alguns autores, o substantivo abstrato "monumentalidade" geralmente tem seu significado derivado do primeiro, como algo que esteja implícito ou óbvio. Note-se que também os dicionários, grandes definidores de palavras e expressões, se limitam aos significados de monumento e monumental, enquanto a palavra monumentalidade sequer é mencionada.

De certo que o conceito de monumento configura-se como fundamental e útil para alcançarmos uma definição e um entendimento maior sobre a monumentalidade. Porém, como veremos adiante, a monumentalidade, categoria abstrata, ao mesmo tempo que é inerente ao monumento (categoria concreta), também o transcende. Estando presente no monumento, mas indo muito além dele, a monumentalidade mostra-se complexa se deixarmos de nos limitar à realidade empírica imediata e começarmos a nos indagar, por exemplo, sobre o seu significado na construção do espaço, sua origem e seu papel social na história. Realmente a monumentalidade pode até parecer, mas não é óbvia, estando aí talvez a razão de seu limitado tratamento teórico.

Recentemente podemos perceber uma maior atenção prestada por parte de alguns cientistas sociais (entre eles os geógrafos) a temas relacionados a monumentos e à monumentalidade. Vindos sobretudo no bojo da chamada "nova geografia cultural", artigos como os de Westcoat Jr. (1994), Withers (1996) e Boholm (1997) deixam entrever um campo de estudo que finalmente começa a ser investigado. No entanto, esses estudos, de modo geral, não chegam a realizar um tratamento conceitual muito profundo, limitando-se à análise de casos pontuais. Portanto, são demonstradores, por um lado, da importância do papel que a monumentalidade e o monumento apresentam na construção do espaço como campo de significações, e, por outro, são ilustrativos da pertinência de um tratamento mais aprofundado sobre os dois conceitos.

Cabe-nos, aqui, lançar uma perspectiva geográfica sobre esses conceitos, já que, afinal, tanto o monumento quanto a monumentalidade são formas passíveis de espacialização, encenando, portanto, uma relação dialética com as sociedades que as conceberam.

\section{O sentido histórico da monumentalidade}

O conceito de monumento não se limita às obras arquitetônicas ou esculturais tal como apreendidas pelo senso comum. Além destas, são considerados como monumentos também os vários tipos diferentes de documentos escritos e iconográficos, as obras de arte e todo e qualquer elemento ou objeto que expresse a atividade e o pensamento social de uma época.

Em seu artigo intitulado "Documento/Monumento", Jacques Le Goff busca as origens etimológicas dessas duas palavras, e mostra as maneiras diferentes como esses termos têm sido utilizados pelos historiadores ao longo do desenvolvimento da ciência histórica. Vejamos o que escreve este autor sobre monumento: 
A palavra latina monumentum remete para a raiz indo-européia men, que exprime uma das funções essenciais do espirito (mens), a memória (memini). O verbo monere significa 'fazer recordar', donde 'avisar', 'iluminar', 'instruir'. O monumentum é um sinal do passado. Atendendo às suas origens filológicas, o monumento é tudo aquilo que pode evocar o passado, perpetuar a recordação, por exemplo, os actos escritos. Quando Cícero fala dos monumenta hujus ordinis[...], designa os actos comemorativos, quer dizer; os decretos do senado. Mas desde a Antiguidade romana o monumentum tende a especializar-se em dois sentidos: 1) uma obra comemorativa de arquitetura ou de escultura: arco de triunfo, coluna, troféu, pórtico, etc.; 2) um monumento funerário destinado a perpetuar a recordação de uma pessoa no domínio em que a memória é particularmente valorizada: a morte (LE GOFF, 1985: 95; grifos do autor).

Durante muitos séculos, portanto, os monumentos representavam sobretudo os "atos escritos", isto é, documentos políticos e/ou jurídicos, ou ainda, constituíam-se em grandes coleções de documentos ufanando a história de uma nação, de um povo (e seus governantes), ou de uma província. Mesmo até a primeira metade do século XIX ainda serão comuns os "Monumenta Germaniae historica", "Monumenta historiae patrie", "Monumenti di storia patria delle provincie modenesi" e outros (p. 96/97). Só próximo do final do século XIX e início do XX, a história, influenciada pelo Positivismo, passa a preconizar a "objetividade" do documento em detrimento da "intencionalidade" do monumento.

Mas longe de acreditar na simples neutralidade do documento positivista, Le Goff ressalta o caráter ao mesmo tempo verdadeiro e falso de todo documento, uma vez que ele é

o resultado de uma montagem, consciente ou inconsciente, da história, da época, da sociedade que o produziram, mas também das épocas sucessivas durante as quais continuou a viver; talvez esquecido, durante as quais continuou a ser manipulado, ainda que pelo silêncio. O documento e uma coisa que fica, que dura, e o testemunho, o ensinamento [...] que ele traz devem ser em primeiro lugar analisados desmistificando-lhe o seu significado aparente. O documento é monumento. Resulta do esforço das sociedades históricas para impor ao futuro voluntária ou involuntariamente determinada imagem de si próprias (...) (1985: 103; grifo nosso).

O documento permanece como monumento; é, pois, um documento-monumento, “(...) o testemunho de um poder polivalente e, ao mesmo tempo, cria-o" (idem, p. 104). Seja como obra arquitetônica ou escultural ou como documento histórico escrito ou iconográfico, o monumento serve de testemunho do poder. Poder esse que deseja ser legado à memória coletiva a fim de tentar perpetuar-se, "fazendo recordar" às gerações futuras de sua existência, e, mais que isso, "avisando" e "instruindo-as" sobre sua força.

Aloïs Riegl, que viveu na segunda metade do séc. XIX e início do séc. XX, também apresenta um conceito amplo de monumento semelhante ao de Le Goff, apesar de suas análises estarem voltadas especificamente para o que chama de "o culto moderno dos monumentos": em linhas gerais, a valorização dos monumentos como representantes de um período histórico e da arte, cultura e sociedade a ele correspondentes - que começa na Renascença, se afirma no séc. XVIII, e se intensifica no séc. XIX ${ }^{1}$, no ocidente, levando a práticas mais preservacionistas.

Segundo Riegl, num primeiro momento, que se estenderia dos primórdios da história da cultura humana até o fim da Idade Média, teria prevalecido a edificação dos "monumentos intencionais", criados pela vontade de alguns visando sobretudo a exaltação patriótica e/ou a comemoração de um evento importante e, por isso, possuidores de um "valor de rememoração intencional". A partir do Renascimento e da revalorização análoga da arte e história da Antiguidade clássica, os monumentos passam a ser considerados com base no seu valor artístico e histórico, este julgado com referência aos rígidos cânones artísticos do período clássico; mas, no séc. XIX, os "valores de arte" absolutos são questionados, e substituídos pelo valor de arte

1 A intensificação da valorização dos monumentos no século XIX está vinculada a uma concepçao evolucionista da história, bem característica daquele século. É interessante notar como nesse período. paralelamente à forte idéia de progresso, que gerava uma visão evolucionista e desenvolvimentista da humanidade rumo ao futuro, foi feita também uma revalorização de fatos e objetos do passado. 
relativo, que valoriza cada uma das épocas históricas e os monumentos singulares delas derivados, mesmo os aparentemente mais banais (como um simples documento de venda de um cavalo, como exemplifica Riegl): tratar-se-iam dos "monumentos não intencionais" repletos de valor histórico intrínseco, uma vez que trazem em si indícios dos costumes sociais, jurídicos, políticos e econômicos de uma época, sem falar da própria diferença no uso da linguagem, da forma da escrita e das técnicas empregadas na confecção de seus materiais. Englobando tanto os monumentos intencionais quanto os não intencionais é identificada uma terceira classe de monumento - os monumentos antigos -, conjunto de "todas as criações do homem, independentemente de sua significação original, contanto que elas testemunhem a evidência de ter suportado a prova do tempo" (p.47).

Para Riegl, então, todos os tipos de monumentos são dotados de um valor de rememoração, seja ele intencional ou não, e seu maior valor estaria na sua antigüidade, na sua capacidade de resistência à ação do tempo. $\mathrm{O}$ autor acaba direcionando seu estudo sobretudo para os monumentos históricos não intencionais, talvez por considerá-los muito mais numerosos, diversificados e interessantes para o historiador, o qual passa a atribuir valores subjetivos aos monumentos ao escolher com qual(is) trabalhará. Mas aqui também podemos identificar uma diferença entre as amplitudes dos conceitos de Riegl e de Le Goff: enquanto este último ressalta a manifestação do poder no documento/monumento, o primeiro, ao não questionar o porquê da sobrevivência de certos monumentos em detrimento de outros, negligencia a manifestação implícita ou explícita do poder no monumento.

Ainda assim podemos nos utilizar de seus comentários acerca daquela classe de monumentos por ele denominada "intencional". Talvez justamente pelo fato de não estar muito preocupado com o caráter ideológico do monumento, ele pouco discorre sobre a classe de monumentos por ele denominada de intencional, parecendo considerá-la demasiado limitada quando uma tamanha gama de outros monumentos encontra-se à espera de pesquisadores para investigá-la. No entanto, para a investigaçao do monumento e da monumentalidade como uma feição urbana repleta de significações, o traço intencional do monumento - responsável pelo início de sua criação desde as épocas mais remotas da história humana — nos é interessante. Segundo Riegl (p.35),

Por monumento, no sentido mais antigo e verdadeiramente original do termo, entende-se uma obra criada pela mão do homem e edificada dentro do fim preciso de conservar sempre presente e vivo na consciência das gerações futuros a lembrança de tal ação ou tal vida (ou as combinações de uma e de outra).

O monumento é, portanto, um legado à memória coletiva, um legado "criado pela mão do homem" e por ele edificado para carregar consigo toda uma carga de concepções que o farão símbolo de uma mensagem que quis ser passada, de um aviso ou de uma instrução que se desejou transmitir.

A categoria concreta, empírica do monumento não se limita, então, ao objeto, uma vez que ele leva uma carga simbólica, abstrata - sua monumentalidade -, a qual tem por função trabalhar sobre o imaginário social.

Os avisos instrutivos simbolizados no monumento, por sua vez, são ditos através de um monólogo: o monólogo do poder. Erigido como símbolo transmissor de ideologias dominantes na história das sociedades, o monumento, como poder transmutado sobretudo em obra arquitetônica ou escultural, fala por alguns poucos dominantes para uma maioria dominada, da qual a única resposta que se espera deve vir sob a forma de respeito, admiração e até mesmo medo.

O monumento encerra em si uma monumentalidade, a qual, por sua vez, é transcendente, pois ela não é só mais um objeto presente no espaço urbano; ela é idéia, concepção, crença: objetivo simbolizado em objeto-símbolo, mas capaz de viajar no imaginário. Os monumentos diversos (esculturais: em homenagem a pessoas e a fatos históricos; ou arquitetônicos: edifícios, torres, praças, avenidas e planos urbanísticos inteiros) são a própria espacialização de uma idéia, de uma concepção de mundo que procura tanto sua auto-afirmação quanto a subjugação de outras idéias e concepções destoantes. 


\section{Espaço, arquitetura e poder}

Se, como demonstra David Harvey (1992), o controle do espaço (assim como do tempo) por parte das classes dominantes tem servido como fonte de poder social, temos também que o espaço concebido pelas mesmas pode constituir-se um espaço monumentalista, ostentador de grandeza, riqueza e, portanto, de poder. Inclusive esse mesmo autor, em sua obra "The Urban Experience" (1989), trata de um caso tópico, mas bastante ilustrativo, no capítulo intitulado "Monument and Myth", sobre a história da apropriação, por parte de monarquistas e católicos conservadores, de um espaço marcado pela luta e resistência dos comunistas franceses durante a revolução de 1870-1871, feita através da construção da Basílica de Sacré-Coeur em Montmartre. A paisagem parisiense ganhava um monumento panóptico, a fim de não deixar dúvidas sobre quem ganhara a batalha.

Outro autor, Albert E. Elsen (1975), também vincula monumentalidade e autoridade em seu artigo "La arquitectura de la autoridad", ao analisar detalhadamente a riqueza material e, sobretudo, simbólica de obras e elementos arquitetônicos diversos (como portas, escadas, janelas e outros), construídos e utilizados em épocas históricas diferentes, mas que apresentam em comum seus valores propagandísticos. José Mauricio Alvarez (1991), por sua vez, no ensaio "Arquitetura Monumental e Vontade de Potência" mostra que a carga simbólica da arquitetura monumental tem servido como publicidade para o poder de governantes e ideologias dominantes, havendo, assim, uma “(...) coordenação para permitir o triunfo da articulação entre a vontade, a forma e seu significado" (p.10). Este autor, aliás, se inspira em Nietzsche, que considerava a arquitetura "(...) uma espécie de eloqüência do poder" (NIETZSCHE apud ALVAREZ, 1991: 13). Também Adrian Tinniswood (1998) apresenta o desejo de expressão de poder via arquitetura monumental por governantes de todos os períodos, chegando até o final do século XX, em que, mais do que os governos, são as grandes corporações empresariais as responsáveis pelas construções mais expressivas.

A estreita vinculação entre arquitetura, espaço e poder é notada ainda por Michel Foucault (1990: 12), estudioso incansável das práticas e relações de poder, para quem

Seria preciso fazer uma 'história dos espaços' - que seria ao mesmo tempo uma 'história dos poderes' - que estudasse desde as grandes estratégias da geopolítica até as pequenas táticas do habitat, da arquitetura institucional, da sala de aula ou da organização hospitalar; passando pelas implantações econômico-políticas (grifos do autor).

O poder encontra-se, assim, espacialmente representado nos mais diferentes níveis de escalas, desde o global até o pontual. Chama a nossa atenção sobretudo a escala urbana, nível privilegiado de disposição de objetos arquitetônicos e de planos organizadores do espaço, denotadores de mudanças políticas, sociais e econômicas importantes.

Sobre a utilização da arquitetura pelo poder, Foucault nota as diferenças qualitativas de ambos ao comparar uma sociedade estruturada em relações de tipo feudal (vigente ainda até o século XVIII) com a sociedade capitalista. Analogamente as mudanças ocorridas nas formas de se exercer o poder, teríamos a utilização de um tipo diferente de organização espacial e de arquitetura (FOUCAULT, 1990).

Segundo aquele autor, o poder exercido até o séc. XVIII ter-se-ia baseado na teoria políticojurídica da soberania, reativada a partir do Direito Romano, que se referia basicamente "à mecânica geral do poder, à maneira como este se exercia, desde os níveis mais altos até os mais baixos (...). Com efeito, o modo como o poder era exercido podia ser transcrito, ao menos no essencial, nos termos da relação soberano-súdito" (1990: 187). A este poder soberano, interagente com um poder eclesiástico, teria correspondido uma arquitetura que

(...) respondia sobretudo à necessidade de manifestar o podem; a divindade, a força. O palácio e a igreja constituíam as grandes formas, às quais é preciso acrescentar as fortalezas; manifestava-se a força, manifestava-se o soberano, manifestava-se Deus. A arquitetura durante muito tempo se desenvolveu em torno destas exigências (1990:211). 
Uma arquitetura monumental para um poder absoluto inconteste.

Mas a partir já desde o século XVII, e principalmente a partir do século XVIII, teríamos tido "a invenção de uma nova mecânica de poder, com procedimentos específicos, instrumentos totalmente novos e aparelhos bastante diferentes, o que e absolutamente incompatível com as relações de soberania" (FOUCAULT, 1990: 187). O poder soberano dava lugar a um novo poder, um poder disciplinar, estruturado não como propriedade ou privilégio pessoal de um governante ou classe social, mas sim corno "micropoderes" exercidos no interior da sociedade, para os quais a organização espacial, como meio de dominação, também faz-se fundamental. Daí a percepção, por parte de Foucault (1991) do estabelecimento de uma "micromecânica" ou de uma "microfísica" do poder. Para este autor, a arquitetura torna-se mais específica, mais funcional, quando "(...) no final do século XVIII. começa a se especializar, ao se articular com os problemas da população, da saúde, do urbanismo (...) [e quando] trata-se de utilizar a organização do espaço para alcançar objetivos econômico-políticos" (FOUCAULT, 1990: 211).

Mas a arquitetura deixava de ser primordialmente a arte de simbolizar espacialmente para tornar-se uma edificadora de espaços úteis? Não. Como veremos a seguir, uma coisa não excluiria a outra. Aos micropoderes (poderes de origens variadas, e não "pequenos") não necessariamente correspondem sempre "microespaços".

\section{As concepções de monumento e monumentalidade no espaço urbano moderno}

Tal como no caso do historiador Riegl, a vinculação entre monumento, monumentalidade e poder não tem se constituído em temática privilegiada também entre vários arquitetos, apesar do reconhecimento - por parte de alguns - do caráter simbólico do monumento. E o caso, por exemplo, de arquitetos modernistas do século XX que, interessados sobretudo na discussão da aparentemente irredutível oposição entre funcionalidade e monumentalidade, deixaram de lado tal vinculação, permitindo-nos entrever em suas concepções pretensamente democráticas a permanência de um caminho aberto ao reacionarismo.

Considerando o monumento em seu sentido mais literal de edifício, escultura ou memorial dedicado aos mortos, arquitetos do início do movimento modernista na década de 1920, tais como Walter Gropius, consideravam que "O velho monumento era um símbolo para uma concepção estática do mundo, agora rejeitada" (GROPIUS apud CREIGHTON, 1962: 7). Tal afirmativa pode ser melhor compreendida quando lembramos que entre os preceitos fundamentais da nova arquitetura moderna e de seu respectivo movimento funcionalista (que iniciava sua afirmação nos meios acadêmicos e no planejamento urbano) estava a economia quanto aos ornamentos decorativos, resultante de um planejamento e um desenho arquitetural altamente racionalista que pretendia unicamente - pelo menos em tese - fazer a correspondência restrita entre forma arquitetônica e função social. As novas formas do "Estilo Internacional" vinham, então, em contraposição radical às estéticas neoclássica, eclética e Art Nouveau predominantes no final do século XIX, e bastante propícias ao monumentalismo (RELPH, 1987).

No entanto, a aparente rejeição da monumentalidade devia-se muito mais a uma concepção de monumento que restringia o mesmo simplesmente às formas tomadas até então, formas estas postas a serviço de poderes opressores. Buscando romper com a "arquitetura conservadora" do passado, os modernistas, em seu discurso, rejeitavam uma possível utilização ideológicosimbólica do novo estilo, ambicionando torná-lo um instrumento de construção de uma nova era de liberdade e progresso social, que em nada deveria remeter à arquitetura repressora praticada até aquela data. Para os modernistas, então, o monumento e a monumentalidade tomavam-se coisas do passado, não tendo mais lugar num mundo (pretendido) de práticas democráticas em que os anseios coletivos se sobrepunham às ambições pessoais. Mas, como observa Creighton sobre a afirmativa de Gropius exposta acima:

(...) nas declarações desta sorte que abundaram nos manifestos dos anos 20, a palavra monumento era usada num sentido limitado e muito literal, e a natureza simbólica da composição monumental não foi de maneira alguma descartada na prática. O simbolismo estava afixado a um novo estilo, e a novos planos para edificios. Existe bastante perspectiva agora para entender que o trabalho emergente dos 
anos 20 não foi de modo algum puramente funcional [...] mas tinha, em todas as suas escolas e localidades, um forte caráter de simbolismo.

Era antes a transferência dos empenhos criativos do arquiteto para longe das construções dedicadas a príncipes e soberanos para aqueles dirigidos a amplos propósitos sociais - escolas, projetos habitacionais, comunidades democráticas, fábricas - que estava implicada nas declarações reprovadoras sobre a monumentalidade (CREIGHTON, idem).

Mas logo a discussão sobre a monumentalidade emergiria, talvez tentando justificá-la, já que não havia sido possível mesmo evitá-la.

Thomas H. Creighton, num livro que analisa as diferentes propostas para a edificação de um memorial a Franklin Roosevelt, surgidas a partir de um concurso realizado no início da década de 1960, identifica três definições possíveis para a palavra monumental.

Uma primeira e mais limitada definição para monumental seria a de uma característica "pertencente a, apropriada para, ou ocorrente num monumento [...], restringindo o caráter da monumentalidade a um edifício, coluna, pedra, ou similar, erigidos em memória dos mortos, ou de uma pessoa, evento, etc.” (p.7). Uma segunda e mais ampla definição, segundo Creighton, coloca a monumentalidade num sentido mais amplo de algo "servindo como um monumento, um memorial" (idem; grifos do autor), não um monumento "puro" para pessoas ou eventos, mas mesclado, embutido em fachadas de edifícios, centros comunitários e jardins.

As duas primeiras definições deixam-nos entrever uma diferenciação feita entre a simples concretude do monumento dirigido à memória de pessoas ou fatos históricos e a monumentalidade presente em obras arquitetônicas diversas, que "serve como monumento, como memorial". O autor não aprofunda uma explicação sobre esses dois significados, mas enquanto na primeira definição o monumento está restrito a um objeto concreto destinado à preservação da memória coletiva (significado que se assemelha ao que Riegl chama de monumento intencional), na segunda o monumento aparece com um conotação um pouco mais explícita de algo que simboliza, que significa. Porém, em nenhum momento é citado que o monumento (seja em um ou outro significado específico) e a monumentalidade são elementos (por um lado concreto e por outro abstrato) destinados sobretudo à memória preservadora ou à simbolização de um poder, e, portanto, mantenedores e simbolizadores de idéias e valores impressos no espaço, muitos dos quais têm sido marcados pela vontade de atravessar o tempo.

A segunda definição se alia à terceira em sua subjacente "desideologização" do monumento e da monumentalidade. Nessa, a monumentalidade faz parte "da natureza de um monumento, daí este ser sólido e duradouro, impressionante" (p. 8, grifo do autor). A "naturalização" da monumentalidade presente nos monumentos não deixa mais dúvidas sobre a simplicidade e mesmo sobre a (proposital?) insuficiência com que conceitos tão importantes para a construção das cidades, como o são os de monumento e monumentalidade - uma vez que nelas encontramse presentes quase sistematicamente - têm sido tratados.

A aceitação da "monumentalidade por decorrência" (p. 8) teria acabado com a rejeição, por parte dos modernistas, da expressão "monumento moderno" antes considerada um paradoxo por contrapor uma temporalidade passada (voltada à preservação da memória) e uma temporalidade atual, voltada para o futuro do progresso social, econômico e científico-tecnológico. O termo "monumento moderno" ampliava inclusive sua significação (já mesmo antes, no final do século XIX), não se restringindo mais às obras arquitetônicas ou esculturais, passando a ser aplicado também às obras mais representativas da engenharia, como represas, usinas hidrelétricas, pontes, portos e outros objetos espaciais.

Esses monumentos da engenharia (e também os da arquitetura) eram considerados diferentes dos monumentos tradicionais. Enquanto esses últimos eram vistos como tendo sua "grandeza e dominação" voltadas "para o benefício da realeza, da nobreza e do poder" (terrestre ou celeste), os primeiros estariam baseados num "espírito democrático", como afirmava, por exemplo, o primeiro presidente do Tennessee Valley Authority (TVA), Arthur E. Morgan (apud CREIGHTON, idem). O caráter ideológico do monumento é atribuído, aqui, apenas àqueles ligados à nobreza e à realeza, classes dominantes por vários séculos de certo, mas suplantadas nos últimos pela burguesia. Os "democráticos" monumentos modernos (para não dizer burgueses) são considerados como obras para o benefício de toda a sociedade, embora tenham se transformado em instrumentos poderosos tanto para o controle do espaço, para o aumento dos lucros, como 
também para a construção de um imaginário social que vincula o progresso social ao econômico.

A naturalização do monumento e seu novo "espírito democrático", isto é, sua mais recente desideologização, geraram, então, “(...) a tese de que a monumentalidade era simplesmente uma questão de escala, a adição de qualidades emocionais às funcionais, e um fator da hierarquia de tipos e usos de edifícios" (CREIGHTON, p. 8).

Durante a década de 1940, a utilização da monumentalidade como instrumento de demonstração de poder e de dominação (sobretudo pela Itália fascista e pela Alemanha nazista) estava bastante clara, mas, mesmo assim, alguns arquitetos se reuniram em volta do objetivo de busca de uma "nova monumentalidade". E mais uma vez era buscada uma monumentalidade não opressora, e também uma arquitetura que não se limitasse apenas à funcionalidade (como se alguma vez ela realmente o tivesse feito), mas que fosse capaz de causar nas pessoas um "impacto emocional", fazendo-as se identificarem com o espaço circundante. Em 1949, o arquiteto Matthew Novicki (apud CREIGHTON, idem) escreve que

o problema controverso da monumentalidade [...] não depende, de fato, de nenhuma forma, mas é um problema de escala, [...] a monumentalidade, no sentido de contraste entre a arquitetura de importância excepcional e o tamanho de um indivíduo, tem suas verdadeiras e eternas qualidades, da quais o homem não deve ser privado.

Novicki dá tanta importância à escala da construção, que para ele a forma e o estilo parecem menos importantes: a monumentalidade em si é colocada como uma necessidade, uma forma primordial de interação do indivíduo com o espaço em que a comparação do observador com o objeto observado/admirado deve proporcionar ao primeiro uma sensação de êxtase. Mas o espaço monumental não deveria servir ao uso corpóreo, e sim a um uso simbólico: ele deve emocionar o espectador, tal como um espetáculo cenográfico o faz.

Mas nem todos eram da mesma opinião que Novicki. Para outros arquitetos a "nova monumentalidade" deveria estar imbuída de um caráter de representação coletiva, segundo eles, própria dos tempos modernos. A monumentalidade do passado, especialmente a do século anterior não era mais capaz de atender às necessidades de representação da nova sociedade que se pretendia construir: a nova monumentalidade seria elemento fundamental de uma utopia que, na verdade, já não era tão nova assim, tendo suas raízes nos séculos anteriores.

Em 1943, Sigfried Giedion, Fernand Léger e José Luis Sert (apud FRAMPTON, 1997: 270) elaboram um documento que recebe o título de "Nove Pontos sobre a Monumentalidade", defendendo a elaboração de uma nova monumentalidade para as cidades. Vejamos cinco desses pontos:

1) Os monumentos são marcos humanos que os homens criaram como símbolos de seus ideais, objetivos e atos. Sua finalidade é sobreviver ao período que lhes deu origem e constituir um legado às gerações futuras. Enquanto tais, formam um elo entre o passado e o futuro.

2) Os monumentos são a expressão das mais altas necessidades culturais do homem. Devem satisfazer à eterna exigência das pessoas, que desejam ver sua força coletiva transformada em símbolos. Os monumentos mais vitais são aqueles que expressam o sentimento e as idéias dessa força coletiva - o povo.

3) Os últimos cem anos testemunharam a desvalorização da monumentalidade. Isto não significa que exista ausência alguma de monumentos formais ou exemplos arquitetônicos que pretendam servir a essa finalidade; com raras exceções, porém, os chamados monumentos dos últimos tempos transformaram-se em fachadas vazias. De modo algum representam o espírito e o sentimento coletivo dos tempos modernos.

4) Um novo passo está à nossa frente. As mudanças do pós-guerra em toda a estrutura econômica das nações podem trazer consigo a organização da vida comunitária na cidade, que foi praticamente ignorada até o presente momento.

5) As pessoas querem que os edifícios que representam sua vida social e comunitária proporcionem algo além da mera satisfação funcional.

A nova monumentalidade proposta pelos modernos deveria servir para fins mais democráticos, populares, erigindo obras com as quais as comunidades urbanas se identificassem, 
uma vez que as representariam, e não ao Estado centralizador. Daí também o desejo de rompimento com a monumentalidade do passado, com uma monumentalidade simbolizadora de poderes individuais ou classistas: os novos monumentos deveriam simbolizar as idéias e os ideais de uma força coletiva popular.

Tal proposta suscita questões difíceis. Pois se a imbricação entre monumentalidade e poder foi sempre constante, seria possível uma monumentalidade sem um caráter opressor ou manipulador? E a monumentalidade realmente uma "necessidade cultural do homem", ou dos governantes, das classes dominantes e dos arquitetos que lhes servem?

Os novos monumentalistas, tomados por um ideal utopista de valorização da "organização da vida comunitária na cidade", acabaram, ainda, por cometer um erro comum entre vários utopistas do passado: homogeneizaram "as pessoas que desejam ver sua força coletiva transformada em símbolos", e se esqueceram que as grandes encomendas arquitetônicas costumam vir da parte dos governos e das grandes empresas, e que ambos constantemente tomam os seus interesses privados como sendo os interesses da coletividade.

A oposição entre funcionalidade e monumentalidade nos parece algo muito mais forjado do que real ${ }^{2}$. Isso porque por mais que se pretenda mais racional e menos simbolista, a arquitetura moderna inicial nunca deixou a monumentalidade realmente de lado, e esta é sempre expressiva - mesmo que seja uma expressão de frieza e distanciamento. Por outro lado, a própria eficácia funcional pretendida pelos modernistas tem sido alvo de críticas (LEFEBVRE, 1963; SANTOS, 1988); uma ineficácia que muito se deve à transposição de modelos rígidos de planejamento para escalas espaciais mais amplas, modelos que pretendendo-se tão funcionais acabam por mostrar-se menos práticos e mais exibidores de uma técnica cujo narcisismo descambou, como não poderia deixar de ser, para a monumentalidade.

À rigidez da arquitetura e do planejamento modernos vem se contrapondo, nas últimas três ou quatro décadas, a arquitetura e o projeto (o termo planejamento perde espaço) ditos pósmodernos. Considerando as obras modernistas repressivas, abstratas, feias, estéreis, antisociais e expressivas de um autoritarismo arrogante, os arquitetos pós-modernos parecem não identificar, no entanto, a monumentalidade de muitas dessas obras, ou o fazem, mas buscam um outro tipo de monumentalidade própria e qualitativamente distinta. Diferenciando os pós-modernos dos modernos, afirma Teixeira Coelho (1986: 69/70; grifos do autor):

(...) No lugar do desastre modernista, propõe-se um reencontro com formas arquiteturais presentes na memória coletiva dos povos, formas retiradas da linguagem histórica da arquitetura, mas não tais quais e, sim, retrabalhadas, reinterpretadas. No lugar da "máquina de habitar" (...) ressurge a noção da arquitetura como monumento, monumento à vida, ao espaço: e a arquitetura da forma livre, a arquitetura como festa.

A partir da colagem e do ecletismo estilístico, a arquitetura pós-moderna declara-se abertamente favorável a um simbolismo de leitura imediata, buscando fazer-se uma "arquitetura do espetáculo" (HARVEY, 1992). Um espetáculo de saturação do repertório arquitetônico, segundo Otília Arantes (2000), que, analisando as fachadas da Strada Novissima (uma rua artificial composta de fachadas vazias apresentada na Bienal de Veneza em 1980), nela ressalta seu caráter teatral e cenográfico capaz de gerar uma sensação de irrealidade. Sobre a teatralidade de outra composição exemplar do pós-modernismo a Piazza d'Italia, de Charles Moore, localizada em Nova Orleans, Harvey (p. 95) observa que

(...) A arquitetura e o projeto urbano dessa espécie transmitem sobretudo um sentido de alguma busca de um mundo de fantasia, da "viagem" ilusória que nos tire da realidade corrente e nos leve à imaginação pura.

A atitude provocativa e irônica do pastiche arquitetônico pós-moderno, buscando uma fuga, favorece também a alienação daqueles a quem cabe a sua leitura. Altamente fetichista, nessa "arquitetura obscena”, como a chama O. Arantes (2000: 271), “(...) o tom contestatório [em

2 Nem mesmo a arquitetura praticada antes da moderna era puramente monumentalista. A despeito de todo simbolismo, já as obras arquitetônicas antigas conjugavam com este utilidades práticas. Exemplos são os banhos imperiais romanos, o Coliseu e os castelos medievais com suas ameias para defesa, descritos por ELSEN (op. cit.). 
relação ao Movimento Moderno] não é dominante, nem tão radical assim, como muitos pretendem". Pelo contrário, pois num mundo globalizado em que a competição interurbana se revela pela tentativa das cidades de transmitirem uma imagem positiva para os empreendimentos econômicos,

(...) Tomar o popular como referência, ou a feição mais banal da sociedade de consumo são iniciativas que têm o seu preço, como uma maior integração na ordem capitalista: não é fácil precisar onde termina a ruptura (via de regra espalhafatosa) com o passado e principia a mera atualização. Para bem ou para mal, a arquitetura obscena se encontra como um peixe dentro d'água em pleno centro nevrálgico do atual estado de coisas (ARANTES, 2000).

Com seu monumentalismo celebrativo e espetacular, os pós-modernos conferem novas formas alienantes às cidades dominadas pelo ideário neoliberal que busca decretar o fim das utopias. Nesse sentido, o monumentalismo decadente de suas "fachadas vazias" e a-históricas parece implicar numa perda do caráter solene da monumentalidade e no esvaziamento de seus simbolismos historicamente apresentados.

O papel pedagógico da monumentalidade volta-se, assim, para uma celebração do consumo pelo consumo, traduzindo um movimento que exprime a decadência do projeto dos modernos a partir do pastiche de simbologias degradadas.

A monumentalidade, quer dos clássicos, modernos ou pós-modernos, faz-se documento tanto da história como da geografia de uma sociedade: ela simboliza o poder e aquilo que este escolhe para ser transmitido às pessoas do presente e do futuro. Sua monumentalidade deriva da intenção de fazer do espaço urbano um palco com cenografia exuberante capaz de gerar emoções, reviver tradições e repactuar relações através do "espetáculo" assistido de perto ou de longe. Pois a força da monumentalidade não se limita ao controle daqueles a ela diretamente subordinados, uma vez que ela será idéia e imagem transpostas ao espaço e, num caminho inverso, espaço transposto às idéias e às imagens - e estas não são fixas, elas são fruto e semente do imaginário. Está aí o maior poder do monumento/da monumentalidade: estar nos lugares e no imaginário.

Resumo: CIDADE, MONUMENTALIDADE E PODER. Este artigo pretende chamar a atenção para a monumentalidade como uma estratégia utilizada de maneira renitente pelo Poder na construção do espaço urbano, fato que, no entanto, nem sempre foi apontado. A fim de tornar clara essa relação entre monumentalidade e poder, a pesquisa inclui os modos como historiadores e arquitetos (especialmente os modernos e os pós-modernos) têm concebido as idéias de monumento e de monumentalidade.

Palavras-chave: monumentalidade urbana, poder.

Abstract: CITY, MONUMENTALITY AND POWER. This paper intends to attract attention to monumentality as a strategy renitently used by Power in the construction of urban space, a fact, however, not always observed. In order to make clear this relation between monumentality and power, the research includes the ways historians and architects (specially the modern and post-modern ones) have been conceiving the ideas of monument and monumentality.

Keywords: urban monumentality, power.

\section{Bibliografia}

ALVAREZ, José Mauricio (1991). Arquitetura Monumental e Vontade de Potência. Rio de Janeiro: Oficina Letras \& Artes.

ARANTES, Otília (2000). Arquitetura simulada. In: NOVAES, Adauto (Org.).O Olhar. São Paulo: Companhia das Letras, $8^{\text {a }}$. ed.

BENEVOLO, Leonardo (1983). História da Cidade. São Paulo: Perspectiva.

BOHOLM, Åsa (1997). Reinvented histories: medieval Rome as memorial landscape. Ecumene, Londres: Arnold, v.4, n.3, p. 247-272.

COELHO, Teixeira (1986). Moderno e Pós-Moderno. Porto Alegre: L\&PM.

CREIGHTON, Thomas H. (1962). The Architecture of Monuments. The Franklin Delano Roosevelt Memorial Competition. Nova York: Reinhold Publishing Corporation.

ELSEN, Albert E. (1975). La arquitectura de la autoridad. In: ELSEN, Albert E.; LANE, Barbara M. Arquitectura como símbolo de poder Barcelona: Cuadernos Infimos.

FOUCAULT, Michel (1990). Microfisica do Poder. Rio de Janeiro: Graal, $9^{\circ}$. ed. 
.(1991). Vigiar e Punir. Petrópolis: Vozes, 9ª ed.

FRAMPTON, Kenneth (1997). História Crítica da Arquitetura Moderna. São Paulo:Martins Fontes.

HARVEY, David (1989). The Urban Experience. Baltimore: The Johns Hopkins University Press. Cap. 7: Monument and Myth: The Building of the Basilica of the Sacred Heart.

.(1992). Condição pós-moderna. São Paulo: Loyola, $5^{\mathrm{a}}$. ed.

LEFEBVRE, Henri (1963). Introdução à Modernidade. Rio de Janeiro: Paz e Terra. Cap. 7: Notas Sobre a Cidade Nova.

(1999). A revolução urbana. Belo Horizonte: Ed. UFMG. Cap. 2: O campo cego.

LE GOFF, Jacques (1985). Documento/Monumento. Enciclopédia Einaudi, Porto: Imprensa Nacional - Casa da Moeda, v. 1, p. 95-106.

MUMFORD, Lewis (1982). A Cidade na História: suas origens, transformações e perspectivas. São Paulo: Martins Fontes/Edunb, 2a . ed.

RELPH, Edward (1987). The modern urban landscape: 1880 to the present. Londres: Croom Helm.

RIEGL, Aloïs (1984). Le culte moderne des monuments: Son essence et sa genèse. Paris: Éditions du Seuil.

SANTOS, Carlos Nelson Ferreira dos (1988). Cidade como um jogo de cartas. Niterói: EDUFF, 1988.

TINNISWOOD, Adrian (1998). Visions of Power: Ambition and Architecture from Ancient Rome to Modern Paris. Londres: Mitchell Beazley.

WESTCOAT Jr., James L. (1994). The scale(s) of dynastic representation: monumental tombgardens in Mughal Labore. Ecumene, Londres: Arnold, v.1, n. 4, p. 324-348.

WITHERS, Charles W. J. (1996). Place, Memory, Monument: memorializing the past in contemporary Highland Scotland. Ecumene, Londres: Arnold, v. 3, n. 3, p. 325-344. 